\title{
Peningkatan Manajemen Usaha Ekowisata Mangrove pada Kelompok Sadar Wisata Polaria Tanjungpagar di Desa Mendalok
}

\author{
Yeni Hurriyani ${ }^{1}$, Arfena Deah Lestari ${ }^{2}$ \\ Universitas Tanjungpura ${ }^{1,2}$ \\ yeni.hurriyani@faperta.untan.ac.id ${ }^{*}$, arfenadeah@gmail.com
}

\begin{abstract}
Mendalok Village is located in the northern coastal region of West Kalimantan which has a potential of 10 hectares of mangrove forest. The problem experienced by partners is the lack of knowledge and skills in developing a mangrove ecotourism business. The financial management is still very simple and the potential of existing mangrove forest products is only sold in fresh form at low prices. The method of implementing this program includes training and guidance on business financial book keeping management, how to make various processed products of mangrove forest products, as well as promotional strategies for tourism business and product marketing from partners. After the training and mentoring on ecotourism business management, the level of understanding of the participants were increased. Participants are able to do neat book keeping either through recording in an accounting book or an excel program. Participants were also able to process mangrove fruit and clam meat, become processed foods and drinks, and make souvenirs from shells and snails. Participants were also able to process mangrove fruit become processed foods and drinks. The partners also get insight in the development of ecotourism business in the future so that it becomes more developed and advanced.
\end{abstract}

Keywords: Ecoutourism; Mangrove; Bussiness Management.

\begin{abstract}
Abstrak
Desa Mendalok merupakan desa yang berada di kawasan pesisir utara Kalimantan Barat yang mempunyai potensi hutan mangrove seluas 10 hektar. Permasalahan yang dialami oleh mitra yaitu Pokdarwis Polaria Tanjung Pagar adalah minimnya pengetahuan dan keterampilan dalam pengembangan usaha ekowisata mangrove. Manajemen keuangan Pokdarwis masih sangat sederhana dan potensi hasil hutan mangrove yang ada hanya dijual dalam bentuk segar dengan harga rendah. Metode pelaksanaan program ini meliputi pelatihan dan bimbingan tentang manajemen pembukuan keuangan usaha, cara membuat aneka produk olahan hasil hutan mangrove baik buah mangrove, kerang maupun siput dan souvenir berbasis cangkang kerang dan siput serta strategi promosi usaha wisata dan pemasaran produk dari mitra. Setelah dilaksanakan pelatihan dan pendampingan manajemen usaha ekowisata terlihat tingkat tingkat pemahaman peserta dalam hal ini anggota pokdarwis sekaligus merupakan pengelolan kawasan ekowisata mangrove polaria menjadi lebih baik. Peserta sudah bisa melakukan pembukuan dengan rapi baik melalui pencatatan di buku akuntansi maupun program excel. Peserta juga sudah mampu mengolah buah mangrove menjadi olahan makanan dan minuman. Para pengelola juga mendapatkan insight dalam pengembangan usaha ekowisata ke depan sehingga menjadi lebih berkembang dan maju.
\end{abstract}

Kata Kunci: Ekowisata; Mangrove; Manajemen usaha. 


\section{A. PENDAhuluan}

Hutan mangrove merupakan ekosistem alamiah yang mempunyai nilai ekologis dan ekonomis tinggi. Hutan ini menyediakan bahan dasar untuk keperluan rumah tangga dan industri, seperti kayu bakar, arang, kertas dan rayon, yang dalam konteks ekonomi mengandung nilai komersial tinggi. Hutan mangrove memiliki fungsi-fungsi ekologis yang penting, antara lain sebagai penyedia nutrien, tempat pemijahan (spawning grounds), tempat pengasuhan (nursery grounds) dan tempat mencari makan (feeding grounds) bagi biota laut tertentu. Ekosistem hutan mangrove merupakan tipe sistem fragile, yang sangat peka terhadap perubahan lingkungan. Ekosistem ini, pada kawasan tertentu bersifat open acces, sehingga meningkatnya eksploitasi oleh manusia akan menurunkan kualitas dan kuantitasnya (Bengen, 2002).

Pada beberapa dekade terakhir ini, pemanfaatan hutan dan ekosistem mangrove terus meningkat bukan saja dari segi pemanfaatan lahannya, tetapi juga segi pemanfaatan pohon mangrovenya, baik secara tradisional maupun komersial. Untuk mengurangi kerusakan dan melestarikan fungsi biologis dan ekologis ekosistem hutan mangrove, perlu suatu pendekatan yang rasional di dalam pemanfaatannya, dengan melibatkan masyarakat di sekitar kawasan dan masyarakat yang memanfaatkan kawasan hutan mangrove secara langsung. Hutan mangrove dengan keunikan yang dimilikinya, merupakan sumberdaya alam yang sangat berpotensi untuk dijadikan sebagai tempat kunjungan wisata. Hutan mangrove merupakan sumber daya alam yang dapat di manfaatkan menjadi salah satu objek wisata yang menarik bagi pengunjung. Penerapan sistem ekowisata di ekosistem hutan mangrove merupakan salah satu pendekatan dalam pemanfaatan ekosistem hutan mangrove secara lestari (Sudiarta, 2006).

Desa Mendalok merupakan salah satu desa yang terletak di pesisir Kabupaten Mempawah Kalimantan Barat yang mempunyai kawasan hutan mangrove seluas 10 Ha. Sejak November 2017, kawasan hutan mangrove ini seluas $500 \mathrm{~m}^{2}$ dikelola menjadi kawasan ekowisata dan dikenal dengan nama Wisata Mangrove Polaria Tanjung Pagar. Pembentukan kawasan wisata ini diinisiasi oleh Kelompok Sadar Wisata (Pokdarwis) "Polaria Tanjung Pagar" yang dibentuk oleh kepala desa bersama masyarakat.

Kawasan ekowisata dihadirkan sebagai salah satu upaya untuk menghadirkan konsep wisata dengan tidak mengabaikan keberlangsungan lingkungan. Salah satu keunggulan dari ekowisata adalah merupakan suatu konsep pengembangan pariwisata yang berkelanjutan dengan tujuan mendukung upaya-upaya pelestarian lingkungan baik alam maupun budaya serta dapat meningkatkan partisipasi aktif masyarakat dalam pengelolaan dengan tujuan akhir agar masyarakat dan pemerintah setempat mendapatkan manfaat ekonomi, dan memberikan peluang kepada generasi muda dan yang akan datang untuk memanfaatkan dan mengembangkan potensi tersebut (UNESCO, 2009; Sudiarta, 2006). Keikutsertaan masyarakat dalam ekowisata tentunya akan berdampak positif dalam segi lingkungan dan ekonomi karena jika masyarakat merasakan manfaat dari ekowisata tersebut sudah pasti sumberdaya dan potensi yang ada tidak akan dirusak dan nilai jual kawasan beserta investasinya menjadi lebih tinggi

Pokdarwis "Polaria Tanjung Pagar" merupakan bentuk kelembagaan informal yang dibentuk pemerintah desa dan anggota masyarakat memilki keterkaitan dan peran 
penting dalam mengembangkan dan mewujudkan Sadar Wisata dan Sapta Pesona di Desa Mendalok. Keberadaan Pokdarwis dalam konteks pengembangan destinasi pariwisata berperan sebagai salah satu "unsur penggerak" dalam turut mendukung terciptanya lingkungan dan suasana yang kondusif di tingkat lokal di daerahnya, yang secara kolektif akan berdampak positif bagi perkembangan destinasi pariwisata dalam konteks wilayah yang lebih luas. Peran dan kontribusi Pokdarwis tersebut perlu terus didukung dan dikembangkan baik secara kualitas maupun kuantitas dalam turut menopang perkembangan dan pertumbuhan destinasi pariwisata, maupun khususnya peningkatan peran masyarakat dalam pembangunankepariwisataan di daerahnya masing-masing.

Permasalahan yang dialami oleh mitra yaitu Pokdarwis "Polaria Tanjung Pagar" yang ada di Desa Mendalok Kecamatan Sungai Kunyit Kabupaten mempawah adalah minimnya pengetahuan dalam mengelola usaha ekowisata yang baru dikembangkan. Sampai saat ini, mitra belum pernah mendapatkan pelatihan terkait manajemen usaha ekowisata. Potensi besar yang dimiliki kawasan ekowisata mangrove Desa Mendalok belum tergarap dengan optimal sehingga belum memberikan dampak ekonomi yang berarti bagi masyarakat lokal.

Kawasan ekowisata mangrove "Polaria Tanjung Pagar" yang dikelola mitra hanya sebatas menjual panorama alam dengan sumber pemasukan berasal dari tiket masuk dan parkir. Padahal hutan mangrove dikawasan ini menghasilkan banyak sekali bahan baku seperti buah mangrove yang jika diolah menjadi produk olahan makanan dan minuman tentunya akan menghasilkan produk yang bernilai tinggi. Selain menjadi ikon kawasan ekowisata "Polaria Tanjung
Pagar", tentunya produksi produk olahan ini akan menggerakan perekonomian masyarakat lokal. Sehingga akan berdampak positif terhadap peningkatan perekonomian masyarakat.

Diversifikasi (penganekaragaman) pengolahan hasil hutan mangrove yaitu buah mangrove menjadi produk yang menarik, bermutu, serta mempunyai daya simpan yang lebih lama belum pernah dilakukan oleh mitra. Hal ini disebabkan karena terbatasnya pengetahuan mitra serta keterbatasan fasilitas yang dimilki. Berbagai masalah inilah potensi besar yang dimiliki kawasan mangrove Desa Mendalok belum tergarap dengan optimal.

\section{Pokdarwis "Polaria Tanjung Pagar"}

Desa Mendalok yang menjadi mitra menginginkan suatu inovasi dalam pengembangan usaha ekowisata melalui pemanfaatan hasil hutan mangrove berupa diversifikasi buah mangrove menjadi aneka produk olahan yang memiliki nilai jual tinggi dan dapat dikenal oleh masyarakat di luar desa tersebut. Oleh karena itu, mitra berharap untuk dapat menjalin hubungan kerjasama dengan pihak perguruan tinggi agar dapat memberikan bantuan baik berupa pelatihan manajemen usaha, penerapan teknologi pengolahan buah mangrove, serta sistem pemasaran yang efektif sehingga dapat meningkatkan produktivitas Pokdarwis yang mereka jalankan saat ini.

\section{B. PELAKSAAAN DAN METODE}

Metode pelaksanaan program ini meliputi pelatihan dan bimbingan tentang manajemen pembukuan keuangan usaha, cara membuat aneka produk buah mangrove, serta strategi promosi usaha wisata dan pemasaran produk dari mitra, evaluasi tahap I dan II serta pendampingan untuk pembinaan yang bekerjasama dengan Dinas Pariwisata Kabupaten Mempawah. Pada 
akhir kegiatan akan dilakukan evaluasi terhadap tingkat keberhasilan program yang telah dilaksanakan. Evaluasi akhir dilaksanakan untuk mengetahui hambatan maupun kesulitan yang dihadapi mitra selama berlangsungnya kegiatan dan untuk selanjutnya dicarikan solusi penyelesaiannya.

Upaya untuk meningkatkan pemahaman mitra dilaksanakan dengan transfer pengetahuan dan keterampilan yang sifatnya praktis sehingga lebih mudah dipahami. Keberhasilan program ini tentunya bergantung kepada keseriusan pihak pelaksana program dan kerja sama dari berbagai pihak baik Tim PKM, Mitra dan stakeholder lainnya.

Kegiatan yang akan dilakukan dalam program PKM ini berupa pelatihan dan bimbingan teknis dengan metode ceramah yang disertai alat peraga dan praktek langsung. Pada prinsipnya kegiatan ini meliputi : (1) Bimbingan dan pendampingan tentang manajemen usaha ekowisata mangrove yang tidak sama dengan usaha wisata pada umumnya. Karena dalam usaha ekowisata harus ada tanggung jawab terhadap kelestarian lingkungan, adanya unsur edukasi kepada pengunjung, kegiatan konservasi mangrove yang melibatkan masyarakat sekitar dan pengunjung serta harus memberikan manfaat secara ekonomi bagi masyarakat sekitar. Mitra akan diberi pendampingan dalam bentuk penyusunan modal kerja yang likuid dalam bisnis ekowisata serta penyusunan laporan perencanaan keuangan dan modal kerja ekowisata; (2) Pelatihan dan konseling pengolahan buah mangrove menjadi aneka produk olahan seperti syrup dan dodol mangrove yang memiliki nilai gizi dan jual lebih baik. Tahapan kegiatan dimulai dari pemilihan bahan baku, mempersiapakan alat dan bahan yang dibutuhkan, proses pengolahan produk, pengemasan/packaging produk, dan penyimpanan; (3) Pelatihan dan bimbingan dalam proses pengemasan dan pelabelan produk. Mitra akan diajarkan bagaimana mengemas produk dengan baik sehingga mempunyai daya simpan (durability) yang lama. Selain itu, mitra juga akan diajarkan bagaimana mendesain label produk yang informatif dan menarik; (4) Evaluasi kegiatan yang telah dilakukan.

\section{HASIL DAN PEMBAHASAN}

\section{Orientasi Lapangan dan Sosialisasi Kegiatan}

Orientasi lapangan dan sosialisasi merupakan tahapan awal yang dilaksanakan Program Kemitraan Masyarakat di Desa Mendalok ini. Tujuan kegiatan ini adalah untuk mengetahui kesiapan anggota Pokdarwis untuk melaksanakan keseluruhan program kegiatan PKM ini baik dari segi waktu maupun tempat pelaksanaan. Selain itu, dalam kegiatan ini juga dilaksanakan sosialisasi terkait program-program yang akan dijalankan selama beberapa bulan kedepan. Kegiatan ini dihadiri ketua dan beberapa orang perwakilan pengurus Pokdarwis Polaria Tanjungpagar.

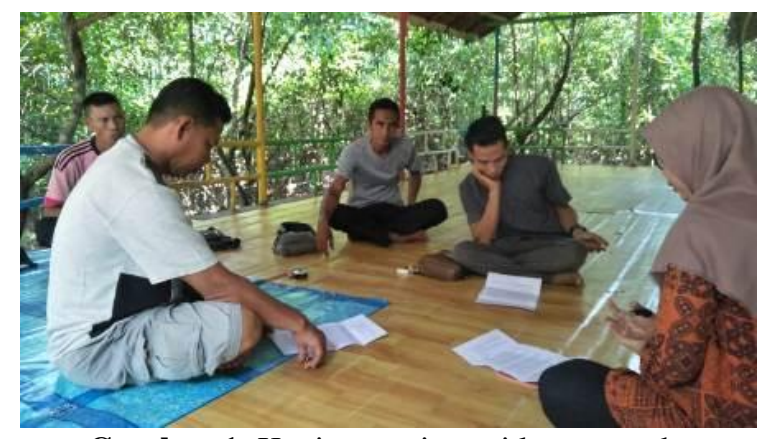

Gambar 1. Kegiatan orientasi lapangan dan sosialisasi kegiatan 
Sebelum dan setelah kegiatan

\section{Pelatihan dan Bimbingan Manajemen Keuangan Usaha Ekowisata}

Usaha ekowisata merupakan kegiatan usaha wisata yang memberi perhatian besar terhadap kelestarian sumber daya alam dan lingkungan yang didorong oleh ketergantungan manusia terhadap sumber daya alam dan lingkungannya serta keberpihakan masyarakat kepada lingkungan. Tujuan usaha ekowisata tidak hanya untuk mencari keuntungan materi semata tetapi juga harus mampu manjabarkan nilai kearifan lingkungan dan sekaligus mengajak orang untuk menghargai apapun yang walaupun tampaknya teramat sederhana. namun kesederhanaan itulah yang menjadi pedoman masyarakat sekitar kawasan wisata mempertahankan kelestarian alamnya. Keterlibatan masyarakat sekitar pada usaha ekowisata ini sangat penting. Masyarakat sekitar menjadi pihak pertama yang mengelola usaha ekowisata sehingga menjadi sumber penghasilan oleh karena itu masyarakat harus dibekali dengan baik pengetahuan manajemen keuangan usaha ekowisata.

Manajemen keuangan merupakan cara pengelolaan keuangan untuk mendapatkan keuntungan dari usaha yang dijalankan dan menggunakan sumber modal dari uang yang ada untuk mengembangkan usaha. Pelatihan manajemen keuangan usaha ekowisata ini dilakukan pada hari Sabtu tangal 20 April 2019. Peserta kegiatan merupakan para pengelola ekowistata Mangrove Polaria yang terdiri dari 15 orang dengan berbagai kalangan usia. Manajemen keuangan diberikan dalam bentuk: (1) Penyusunan modal kerja yang likuid dalam bisnis ekowisata; (2) Penyusunan laporan perencanaan keuangan dan modal kerja ekowisata; (3) Pengenalan program excel dan spreadsheet untuk pelaporan keuangan pelatihan dilakukan peserta diberikan test untuk mengetahui tingkat pemahaman peserta mengenai manajemen keuangan pariwisata. Adapun tingkat pemahaman peserta sebelum kegiatan pelatihan ini dilakukan sangat minim dimana pembukuan yang dilakukan sangat sederhana serta belum ada rencana pengembangan usaha ekowisata yang jelas. Selanjutnya setelah dilaksanakan pelatihan dan pendampingan manajemen usaha ekowisata terlihat tingkat tingkat pemahaman peserta dalam hal ini anggota pokdarwis sekaligus merupakan pengelolan kawasan ekowisata mangrove polaria menjadi lebih baik.

Peserta sudah bisa melakukan pembukuan dengan baik dimana data pemasukan dan pengeluaran sudah dibuat terpisah di buku kas. Pembukuan juga dilakukan menggunakan progam excel dan spreadsheet sehingga memudahkan pengelola dalam penyusunan modal kerja, laporan perencanaan keuangan serta modal kerja ekowisata. Selain itu, para pengelola juga mendapatkan insight dalam pengembangan usaha ekowisata ke depan sehingga menjadi lebih berkembang dan maju.

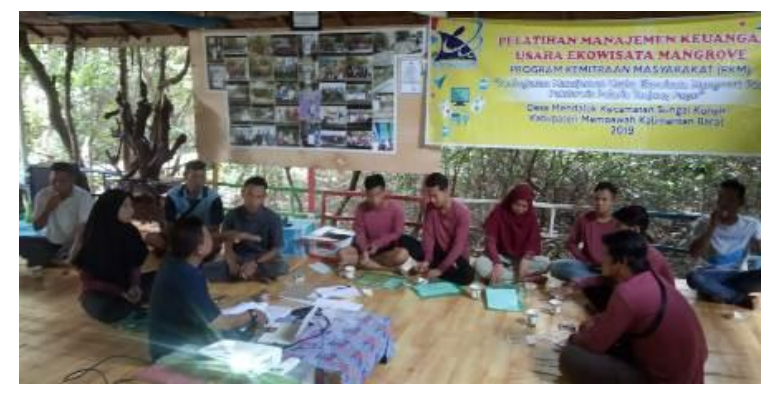

Gambar 2. Pelatihan manjemen keuangan usaha ekowisata 


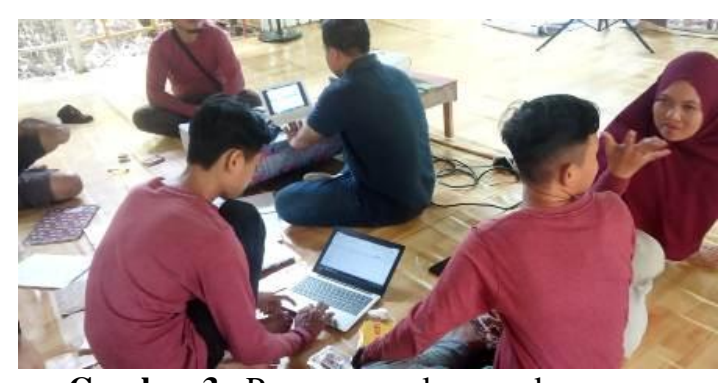

Gambar 3. Penyusunan laporan keuangan menggunakan excell dan spreadsheet

\section{Pelatihan Pengolahan Buah Mangrove}

Buah Mangrove kadang dianggap sebagai 'sampah' oleh sebagian besar masyarakat dan dibiarkan begitu saja. Rasa buah mangrove yang sepat dan asam membuat masyarakat menganggap buah tersebut tidak bermanfaat padahal buah mangrove sebenarnya mengandung banyak vitamin yang dapat diolah menjadi camilan lezat yang memiliki nilai jual. sehingga dibiarkan begitu saja. Tidak semua jenis mangrove dapat diolah menjadi makanan. Dari 63 spesies mangrove, hanya beberapa yang bisa diolah menjadi makanan seperti berembang atau pedada (Sonneratia Sp). Buah ini dapat di oleh menjadi dodol dan sirup (Baderan et al, 2015; Djati et al, 2015; Priyono et al, 2010).

Pelatihan pengolahan buah mangrove ini dihadiri oleh para pengelola ekowistata Mangrove Polaria yang terdiri dari 15 orang dengan berbagai kalangan usia. Pelatihan pengolahan buah mangrove menjadi sirup dan dodol mangrove ini dilakukan bertahap secara berurutan dimulai dari pelatihan pembuatan dodol kemudian dilanjutkan dengan membuat sirup mangrove. Dari pertanyaan yang disampaikan kepada peserta sebelum kegiatan pelatihan ini dimulai seluruh peserta belum pernah membuat makanan dan minuman olahan dari buah mangrove dan tidak memiliki pengetahuan untuk mengolah buah mangrove. a. Pelatihan pembuatan dodol mangrove

Adapun bahan yang digunakan adalah tepung ketan, tepung beras, gula merah, gula pasir, kelapa, minyak nabati, dan buah Pedada itu sendiri. Sedangkan proses pembuatan dodol mangrove sangatlah mudah. Buah pedada dibersihkan lalu dipotong-potong dan dihancurkan dengan blender. Selanjutnya, buah yang sudah hancur kemudian disaring menggunakan saringan besar. Hasil saringan dipisahkan, lalu disaring lagi menggunakan kain untuk mendapatkan sari buah pedada. Setelah itu sari buah dicampur dengan cairan gula merah, santan dan tepung ketan dan tepung beras kemudian diaduk rata. Adonan tersebut dimasak hingga mengental, dan ditambah minyak. Adonan dimasak sambil terus diaduk hingga agak mengeras, setelah itu didinginkan dan siap untuk dikemas.

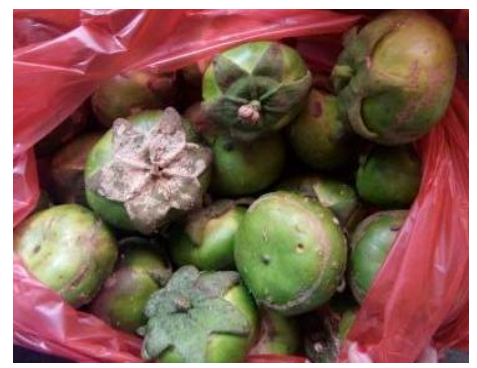

Gambar 4. Buah berembang (Sonneratia sp.) yang digunakan untuk membuat dodol dan syrup mangrove

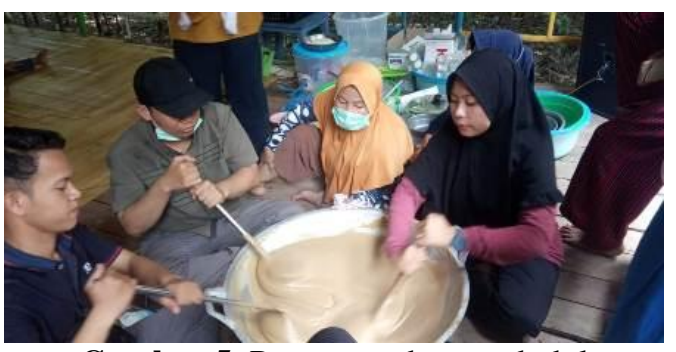

Gambar 5. Proses pembuatan dodol

b. Pelatihan pembuatan syrup Mangrove

Beberapa bahan untuk membuat sirup mangrove adalah buah Sonneratia caseolaris yang telah matang kemudian diambil daging 


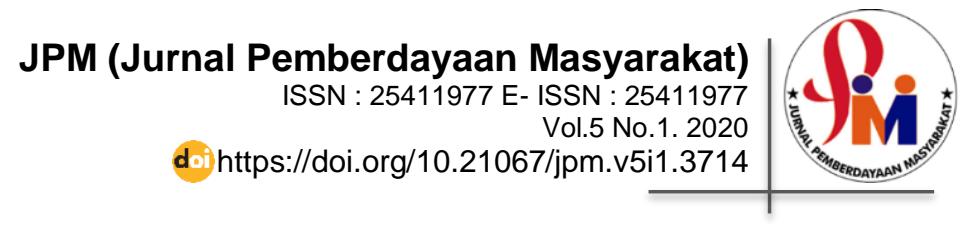

buahnya, lalu digiling halus. Gula pasir, Asam sitrat/sitrun. dan Asam benzoat. Sedangkan cara membuat sirupnya adalah rebus Sonneratia lalu masak dengan gula pasir dan asam sitrat sampai mendidih maksimal, sambil diaduk lalu angkat dari api. Setelah dingin, masukkan asam benzoat agar sirup dapat bertahan lebih lama. Kemudian sirup siap untuk dikemas.

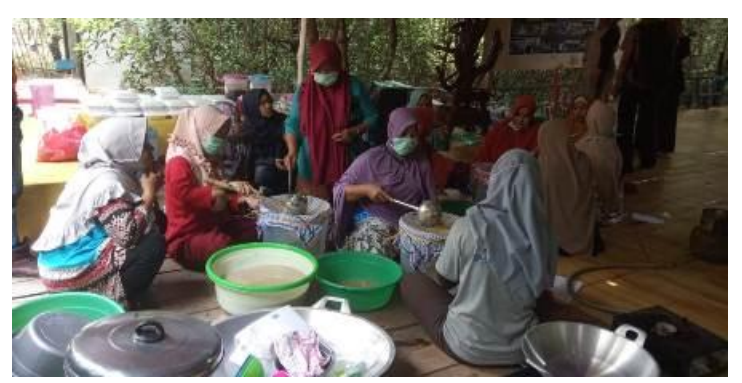

Gambar 6. Proses pembuatan syrup mangrove

\section{Pelatihan Pengemasan dan Pelabelan Produk}

Pengemasan adalah kegiatan merancang dan memproduksi wadah atau bungkus sebagai sebuah produk. Pengemasan adalah aktivitas merancang dan memproduksi kemasan atau pembungkus untuk produk. Biasanya fungsi utama dari kemasan adalah untuk menjaga produk. Namun, sekarang kemasan menjadi faktor yang cukup penting sebagai alat pemasaran (Kottler, 2009; Rangkuti, 2010).

Pada pelatihan ini peserta diajarkan bagaimana mengemas produk dengan baik sehingga mempunyai daya simpan (durability) yang lama. Selain itu, mitra juga diajarkan bagaimana mendesain label produk yang informatif dan menarik.

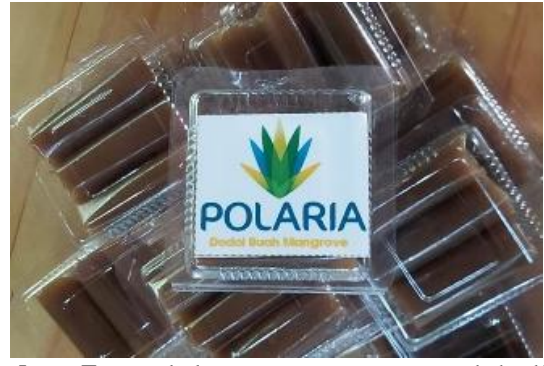

Gambar 7. Dodol mangrove yang sudah dikemas dan diberi label

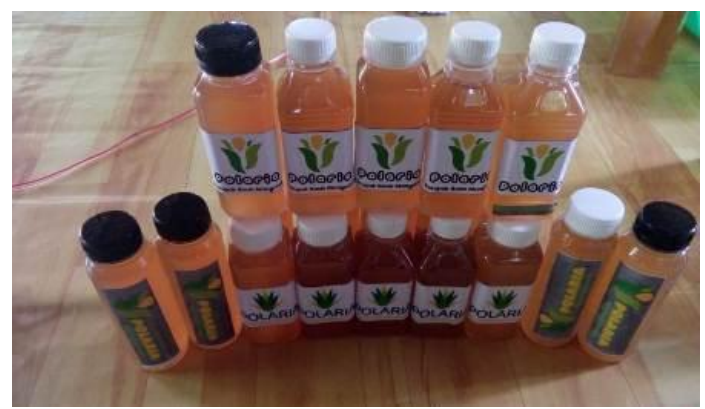

Gambar 8. Syrup mangrove yang sudah dikemas dan diberi label

\section{Simpulan}

\section{PENUTUP}

Setelah dilaksanakan pelatihan dan pendampingan manajemen usaha ekowisata terlihat tingkat tingkat pemahaman peserta dalam hal ini anggota pokdarwis sekaligus merupakan pengelolan kawasan ekowisata mangrove polaria menjadi lebih baik. Peserta sudah bisa melakukan pembukuan dengan rapi baik melalui pencatatan di buku akuntansi maupun program excel. Peserta juga sudah mampu mengolah buah mangrove menjadi olahan makanan dan minuman. Para pengelola juga mendapatkan insight dalam pengembangan usaha ekowisata ke depan sehingga menjadi lebih berkembang dan maju.

\section{Saran}

Pokdarwis diharapkan terus mendapatkan pendampingan oleh dinas pariwisata setempat sehingga usaha ekowisata ini menjadi lebih maju lagi. 


\section{Ucapan Terima Kasih}

Penulis mengucapkan terimakasih kepada Direktorat Riset dan Pengabdian Masyarakat (DRPM) Ditjen Penguatan Risbang Kemenristekdikti yang telah mendanai kegiatan pengabdian kepada masyrakat ini melalui skema program kemitraan masyarakat.

\section{E. DAFTAR PUSTAKA}

Asvi, Z. 2017. Manajemen Badan Usaha Milik Desa (Bumdes) Bina Usaha Desa Kepenuhan Barat Kecamatan Kepenuhan Kabupaten Rokan Hulu. Jurnal Online Mahasiswa 4(2): 1-15

Baderan, D.W.K., Hamidun, M.S., Lamangandjo, C., Retnowati, Y. 2015. Diversifikasi Produk Olahan Buah Mangrove Sebagai Sumber Pangan Alternatif Masyarakat Pesisir Toroseaje, Kabupaten Pohuwato, Provinsi Gorontalo. Pros Sem Nas Masy Biodiv Indon 1(2): 347-351.

Bengen D.G. 2002. Pedoman Teknis Pengenalan dan Pengelolaan Ekosistem Mangrove. Bogor: Pusat Kajian Sumberdaya Pesisir dan Lautan, Institut Pertanian Bogor.

Djajati, S., Rosida, D.F. 2015. Pengembangan Produk Olahan Mangrove Dan Perikanan Di Kawasan Pantai Wonorejo Surabaya. Prosiding Seminar Nasional "Research Month" 2015

Kotler dan Keller. 2009. Manajemen Pemasaran. Jilid I. Edisi ke 13. Jakarta: Erlangga.
Priyono, A., Ilminingtyas, D., Mohson, Yuliani, L.S., Hakim, T. L. 2010. Beragam Produk Olahan Berbahan Dasar Mangrove. Semarang: Kesemat Undip.

Sudiarta, M. 2006. Ekowisata Hutan Mangrove: Wahana Pelestarian Alam dan Pendidikan Lingkungan. Jurnal Manajemen Pariwisata. 5(1): 1-25

Rangkuti, Freddy. 2005. Analisis SWOT: Teknik Membedah Kasus Bisnis. Jakarta: Gramedia.

Sulistiyati, T.D., Puspitasari, Y.E. 2015. Kerupuk Mangrove Antidiare Dari Buah Bakau Rhizopora Mucronata. Journal of Innovation and Apllied Technology 1(1): 82-87

UNESCO. 2009. Ekowisata: Panduan Dasar pelaksanaan. Enviromental Science UNESCO Office. Jakarta. 